Check for updates

Cite this: Mater. Adv., 2020, 1, 197

Received 9th March 2020 Accepted 3rd April 2020

DOI: 10.1039/d0ma00090f

rsc.li/materials-advances

\title{
Deformation of raspberry-like polymer composite particles by colloidal fusion $\dagger$
}

\author{
Shuxia Zhai, Hao Sun, Biwei Qiu and Hua Zou (D) *
}

\begin{abstract}
Colloidal fusion is an emerging method to fabricate core-shell colloidal particles. This work aims to investigate the feasibility of deforming raspberry-like polymer composite particles with polymer coronas by colloidal fusion. Two types of raspberry-like polymer composite particles prepared by seeded emulsion polymerization were attempted. One was submicrometer-sized silica-polystyrene $\left(\mathrm{SiO}_{2}-\mathrm{PS}\right)$ composite particles and another one was micrometer-sized poly(glycidyl methacrylate)-polystyrene (PGMA-PS) composite particles. Initial melting experiments based on submicrometer-sized $\mathrm{SiO}_{2}-\mathrm{PS}$ composite particles were less successful. $\mathrm{SiO}_{2}-\mathrm{PS}$ composite particles with ill-defined core-shell morphologies were fabricated by melting the raspberry-like composite particles in a THF/ethanol medium within $20 \mathrm{~s}$. The effects of different melting parameters including the THF concentration, composite particle concentration, agitation rate and agitation time on the morphology of the composite particles were investigated, which suggested that the level of deformation was mainly affected by the THF concentration. On the other hand, the melting experiments based on micrometer-sized PGMA-PS composite particles in THF/water medium could lead to a well-defined core-shell morphology. The influence of the THF concentration on the morphology of the composite particles was also studied, which indicated that the surface roughness of the composite particles could be easily tuned by varying the THF concentration.
\end{abstract}

\section{Introduction}

Since the pioneering work by Armes in the $1990 \mathrm{~s},{ }^{1-3}$ much attention has been devoted to the synthesis of colloidal polymer composite particles with defined morphology, which is usually critical to tune their physical and chemical properties. ${ }^{4,5}$ The most commonly reported morphologies include core-shell ${ }^{6-12}$ and raspberry-like morphologies. ${ }^{13-39}$ As the name suggests, a raspberry-like polymer composite particle refers to a particle consisting of smaller corona particles attached to the surface of a larger core particle (including inorganic-polymer, polymerinorganic, and polymer-polymer core-corona structures). Due to their high surface roughness, various potential applications such as superhydrophilic coatings, ${ }^{28}$ super-hydrophobic films, ${ }^{29}$ oil/water separation ${ }^{31,36}$ and catalysis ${ }^{32,35}$ have been suggested for raspberry-like polymer composite particles.

In general, there are four strategies for the preparation of raspberry-like polymer composite particles: (1) seeded polymerization (including emulsion polymerization, ${ }^{13-18}$ surfactant-free emulsion polymerization, ${ }^{19}$ miniemulsion polymerization ${ }^{20-23}$ and dispersion polymerization $)^{24-26}$ in the presence of large

School of Materials Science and Engineering, University of Shanghai for Science and Technology, 516 Jungong Road, Shanghai 200093, China.

E-mail: hua.zou@usst.edu.cn

$\dagger$ Electronic supplementary information (ESI) available. See DOI: 10.1039/d0ma00090f polymer or inorganic core particles, in which small polymer corona particles are formed in situ on the core particles; (2) Pickering emulsion polymerization in the presence of small polymer or inorganic corona particles, in which large polymer core particles are formed in situ and stabilized by the smaller particles; ${ }^{27,28}$ (3) sol-gel coating in the presence of large polymer core particles, in which small inorganic corona particles (usually silica particles) are formed in situ on the core particles; ${ }^{29-32}$ and (4) heterocoagulation of large core particles and small corona particles (at least one phase is a polymer) by noncovalent or covalent interactions. ${ }^{33-35}$ Among the above-mentioned methods, seeded polymerization is undoubtedly the most widely used one, ${ }^{18}$ which at least has an obvious advantage in production on a large scale. For example, Liu reported the controllable synthesis of submicrometer-sized $\mathrm{SiO}_{2}$-PS composite particles with a raspberry-like morphology using surface-modified silica particles as seeds. ${ }^{26}$ Zhang et al. fabricated micrometer-sized raspberry-shaped poly(glycidyl methacrylate) (PGMA)-polystyrene (PS) particles via seeded emulsion polymerization using swollen PGMA particles as seeds.

As pointed out by Thickett et al., ${ }^{40}$ morphological control of preformed composite particles (armoured or encapsulated) is particularly important when taking applications into account. For example, armoured particles (raspberry-like particles) may be desirable for materials with functional surfaces, while fully encapsulated particles (core-shell particles) with polymer shells 
are more suitable for film-forming systems. Moreover, the morphological transition of preformed composite particles from raspberrylike to core-shell morphology offers the possibility to further control their surface roughness. In this context, Sacanna et al. recently introduced the concept of "colloidal fusion" for fabricating functional patchy particles from liquid-core colloidal clusters prepared from silicone oil droplets and PS particles via a simple heteroaggregation process. ${ }^{41}$ Driven by surfaceenergy minimization, the hybrid liquid-solid clusters could evolve into particles with a range of patchy surface morphologies on addition of water soluble tetrahydrofuran (THF) as a plasticizer, which allowed the PS spheres to flow under the action of surface tension. In a subsequent study, ${ }^{42}$ the same group proposed a "mix-and-melt reaction" strategy for anisotropic core-shell particle synthesis. The method involved two basic steps: (i) the formation of core-shell clusters by mixing oppositely charged suspensions from positive or negative PS sphere shells and various oppositely charged core materials including silica, hematite, and solid 3-(trimethoxysilyl)propyl methacrylate particles via a simple heteroaggregation process; and (ii) melting the clusters' shells via the addition of the plasticizer THF to the cluster reaction mixture for $20 \mathrm{~s}$, which allowed the PS to flow, to reconfigure, and to fuse together.

Perhaps also pertinent in the context of this work, Okubo et al. reported the variation of the surface unevenness of composite particles produced by the stepwise heterocoagulation of small polymer particles onto a large polymer particle by heat treatment. ${ }^{43}$ When the polymer emulsion was kept at a temperature higher than the $T_{\mathrm{g}}$ of the large particle, the surface of the composite particle was continuously changed from an uneven to a smooth state with the treatment time. Later, Ottewill et al. investigated the preparation of core-shell polymer colloid particles by encapsulation. ${ }^{44}$ First, anionic PS particles were coated with smaller electrosterically stabilized cationic poly(butyl methacrylate) (PBMA) particles by means of heterocoagulation. Second, on heating the heterocoagulated system to a temperature $45{ }^{\circ} \mathrm{C}$ higher than the $T_{\mathrm{g}}$ of PBMA, the PBMA could spread over the surface of the PS particle to give a composite particle with a core-shell structure. Obviously, the colloidal fusion method offers significant advantages over these heating methods. The deformations of the polymer-polymer composite particles in both Okubo's and Ottewill's work are based on heat treatment for hours, while the deformation of $\mathrm{SiO}_{2}-\mathrm{PS}$ particles in Sacanna's work is based on THF as the plasticizer at room temperature for only $20 \mathrm{~s}$.

In the present work, we investigated the feasibility of deforming polymer composite particles with polymer coronas from raspberry-like morphology to core-shell morphology through the colloidal fusion method. As far as we are aware, this is the first time that the colloidal fusion method has been used to deform raspberry-like polymer composite particles prepared by seeded polymerization, which is the primary preparative method for raspberry-like polymer composite particles. Our strategy involves two steps, as shown in Fig. 1. The first step is the synthesis of raspberry-like submicrometer-sized $\mathrm{SiO}_{2}$-PS or micrometer-sized PGMA-PS core-corona composite (a)

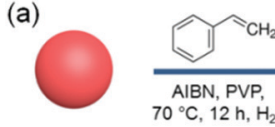

MMS-modified $\mathrm{SiO}_{2}$ particles $70^{\circ} \mathrm{C}, 12 \mathrm{~h}, \mathrm{H}_{2} \mathrm{O}$

Submicrometer-sized raspberry-like $\mathrm{SiO}_{2}-\mathrm{PS}$ composite particles

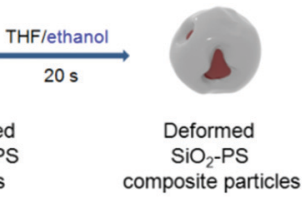

(b)
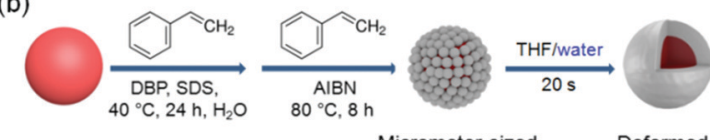

Micrometer-sized Deformed

PGMA particles

composite particles composite particles

Fig. 1 Scheme of the formation and melting of raspberry-like (a) $\mathrm{SiO}_{2}-\mathrm{PS}$ and (b) PGMA-PS core-corona composite particles.

particles by seeded emulsion polymerization of styrene. Then, the raspberry-like polymer composite particles are melted in different media via the addition of THF. The effects of different parameters on the morphology of the composite particles were investigated using SEM and TEM.

\section{Experimental section}

\subsection{Materials}

Styrene (Aldrich) and glycidyl methacrylate (GMA, Aldrich) were passed through a basic alumina column to remove the inhibitor and then stored at $4{ }^{\circ} \mathrm{C}$ prior to use. Tetraethyl orthosilicate (TEOS, Aldrich), ammonium hydroxide solution $\left(\mathrm{NH}_{3} \cdot \mathrm{H}_{2} \mathrm{O}, 28 \%\right.$, Aldrich), ethanol (Sinopharm), 2,2'-azobis(isobutyronitrile)(AIBN, Aldrich), polyvinylpyrrolidone (PVP, K30, $M_{\mathrm{w}}=40000 \mathrm{~g} \mathrm{~mol}^{-1}$, Aldrich), methacryloxymethyltrimethoxysilane (MMS, Gelest), sodium dodecyl sulfate (SDS, Aldrich), dibutyl phthalate (DBP, Aldrich) and THF (TCI) were used as received. Deionized water was used in all experiments.

\subsection{Synthesis of raspberry-like $\mathrm{SiO}_{2}-\mathrm{PS}$ composite particles}

Synthesis of $\mathrm{SiO}_{2}$ particles. $\sim 321 \mathrm{~nm}$ silica particles were synthesized according to the well-known Stöber method. ${ }^{45}$ $63 \mathrm{~mL}$ of absolute ethanol, $9 \mathrm{~mL}$ of ammonium hydroxide solution and $25 \mathrm{~mL}$ of $\mathrm{H}_{2} \mathrm{O}$ were introduced in a $250 \mathrm{~mL}$ threeneck round flask. The mixture was stirred at $300 \mathrm{rpm}$ for $5 \mathrm{~min}$ to homogenize. Then, $4 \mathrm{~mL}$ of TEOS was added into the solution. The mixture was further stirred for $2 \mathrm{~h}$ at room temperature. The silica particles were collected and purified by five centrifugation-redispersion cycles (5000 rpm, $6 \mathrm{~min}$ ), replacing the successive supernatants with ethanol each time. Finally, the particles were redispersed in ethanol (concentration $57.06 \mathrm{~g} \mathrm{~L}^{-1}$ ).

Surface modification of $\mathrm{SiO}_{2}$ particles with MMS. The surface modification of the silica particles with a silane coupling agent MMS can introduce polymerizable vinyl groups onto the silica surface. In a $100 \mathrm{~mL}$ three-necked round flask equipped with a condenser and a magnetic stirrer, $14 \mathrm{~mL}$ of silica particle dispersion was added to a mixture of ethanol $(26 \mathrm{~mL})$ and ammonium hydroxide solution $(20 \mathrm{~mL})$ while agitating, 
followed by the addition of $0.3 \mathrm{~mL}$ of MMS. After agitation for $3 \mathrm{~h}$ at room temperature, the reaction mixture was heated to $70{ }^{\circ} \mathrm{C}$ for $1 \mathrm{~h}$ to promote covalent bonding. The MMS-modified silica particles were purified by centrifugation $(5000 \mathrm{rpm}$, $6 \mathrm{~min}$ ), and washed three times with ethanol and water, respectively. Finally, the particles were redispersed in water (concentration $4.5 \mathrm{~g} \mathrm{~L}^{-1}$ ) and used as the seeds for the subsequent synthesis of the raspberry-like $\mathrm{SiO}_{2}-\mathrm{PS}$ composite particles.

Synthesis of raspberry-like $\mathrm{SiO}_{2}-\mathrm{PS}$ composite particles. The raspberry-like $\mathrm{SiO}_{2}-\mathrm{PS}$ composite particles were synthesized by seeded emulsion polymerization in a $50 \mathrm{~mL}$ three-necked round flask equipped with a condenser and a magnetic stirrer. $22.2 \mathrm{~mL}$ of MMS-modified silica seeds (equivalent to $0.1 \mathrm{~g}$ of dry silica) were mixed with $2.8 \mathrm{ml}$ of water containing $0.2 \mathrm{~g}$ of PVP by ultrasonication at room temperature for $15 \mathrm{~min}$. After degassing with nitrogen for $30 \mathrm{~min}$, the mixture was heated to $70{ }^{\circ} \mathrm{C}$ in an oil bath. The polymerization was initiated by injecting a solution of AIBN (0.01 g) in styrene $(0.5 \mathrm{~g})$ and allowed to continue for $12 \mathrm{~h}$ before cooling down to room temperature. The resulting dispersion was then purified by five centrifugation-redispersion cycles (6000 rpm, $20 \mathrm{~min}$ ), replacing the successive supernatants with ethanol each time. Finally, the particles were redispersed in ethanol (concentration $8.0 \mathrm{~g} \mathrm{~L}^{-1}$ ).

\subsection{Synthesis of raspberry-like PGMA-PS composite particles}

Preparation of PGMA seed particles. $\sim 2.49 \mu \mathrm{m}$ PGMA seed particles were prepared by dispersion polymerization as follows: $3.0 \mathrm{~g}$ of PVP was dissolved in a mixture of $81 \mathrm{~mL}$ of anhydrous ethanol and $9 \mathrm{~mL}$ of water in a $250 \mathrm{~mL}$ three-neck round bottomed flask equipped with a condenser and a mechanical stirrer. After degassing with nitrogen for $30 \mathrm{~min}$, the mixture was heated to $70{ }^{\circ} \mathrm{C}$ in an oil bath. The polymerization was initiated by injecting a solution of AIBN ( $0.2 \mathrm{~g})$ in GMA $(10.0 \mathrm{~g})$ and allowed to continue for $12 \mathrm{~h}$ before cooling down to room temperature. The PGMA particles were collected and purified by three centrifugation-redispersion cycles $(2500 \mathrm{rpm}$, $5 \mathrm{~min}$ ), replacing the successive supernatants one time with ethanol and twice with water. Finally, the particles were dried by freeze-drying.

Synthesis of raspberry-like PGMA-PS composite particles. The raspberry-like PGMA-PS composite particles were synthesized by seeded emulsion polymerization in a $100 \mathrm{~mL}$ threenecked round flask equipped with a condenser and a mechanical stirrer. $0.5 \mathrm{~g}$ of PGMA seed particles, $0.125 \mathrm{~g}$ of SDS and $50 \mathrm{~mL} \mathrm{H}_{2} \mathrm{O}$ were introduced to the round flask. Subsequently, $0.5 \mathrm{~g}$ of DBP and $1.5 \mathrm{~g}$ of styrene were added. After swelling at $40{ }^{\circ} \mathrm{C}$ for $24 \mathrm{~h}$, the mixture was heated to $80{ }^{\circ} \mathrm{C}$ in an oil bath. The polymerization was initiated by injecting a solution of AIBN (0.03 g) in styrene (1.5 g) and allowed to continue for $8 \mathrm{~h}$ before cooling down to room temperature. The resulting dispersion was then purified by three centrifugation-redispersion cycles ( $2500 \mathrm{rpm}, 5 \mathrm{~min}$ ), replacing the successive supernatant one time with ethanol and twice with water. Finally, the particles were redispersed in water (concentration $44.4 \mathrm{~g} \mathrm{~L}^{-1}$ ).

\subsection{Melting of raspberry-like polymer composite particles}

Melting of raspberry-like $\mathrm{SiO}_{2}-\mathrm{PS}$ composite particles. In a typical recipe, an appropriate volume $(0.2-1 \mathrm{~mL})$ of the raspberry-like $\mathrm{SiO}_{2}-\mathrm{PS}$ composite particle dispersion in ethanol was diluted with ethanol to $1 \mathrm{~mL}$ (if the initial volume was less than $1 \mathrm{~mL}$ ). The dispersion was quickly added to an appropriate volume (0.5-3 mL) of a THF/ethanol mixture with 60 vol\% THF, and the mixture was agitated using a vortex mixer (IKA Vortex Genius 3) at grade 1 for $20 \mathrm{~s}$. The deformation was quenched by immediate dilution of the mixture with water. The suspension was subsequently washed by multiple centrifugationredispersion cycles with water. To minimize the effect of the THF gradient during mixing, in each case a freshly prepared THF/ethanol mixture with 60 vol\% THF was used to reach the developing concentration. The THF concentration, composite particle concentration, agitation time and agitation rate were systematically varied.

Melting of raspberry-like PGMA-PS composite particles. The melting experiments were carried out using a similar procedure to that used for raspberry-like $\mathrm{SiO}_{2}-\mathrm{PS}$ composite particles. Typically, $0.5 \mathrm{~mL}$ aqueous dispersion of raspberry-like PGMAPS composite particles was diluted with water to $1 \mathrm{~mL}$. The dispersion was quickly added to an appropriate volume (0.6-7 $\mathrm{mL}$ ) of a THF/water mixture with $40 \mathrm{vol} \% \mathrm{THF}$, and the mixture was agitated using a vortex mixer (IKA Vortex Genius 3) at grade 1 for $20 \mathrm{~s}$. The deformation was quenched by immediate dilution of the mixture with water. The suspension was subsequently washed by multiple centrifugation-redispersion cycles with water. In each case a freshly prepared THF/water mixture with 40 vol\% THF was used to reach the developing concentration. The THF concentration was systematically varied.

\subsection{Characterization}

The morphology of the particles was examined by scanning electron microscopy (SEM, Quanta FEG 450, operating at $30 \mathrm{kV}$ ) and TEM (FEI Tecnai G2 F30, an accelerating voltage of $300 \mathrm{kV}$ ). The SEM samples were sputter-coated with gold prior to observation, and the TEM samples were prepared on carboncoated copper grids. The mean diameter of the particles was calculated from the SEM images by averaging over 50 particles. The intensity-average particle diameters were determined with a Malvern Zetasizer NanozS instrument by analyzing the scattered light at $173^{\circ}$. Thermogravimetric analysis (TGA) was conducted using a PerkinElmer Pyris 1 TGA instrument. The sample was heated in air to $800{ }^{\circ} \mathrm{C}$ at a heating rate of $10{ }^{\circ} \mathrm{C} \min ^{-1}$, and the residue was attributed to $\mathrm{SiO}_{2}$.

\section{Results and discussion}

\subsection{Synthesis of $\mathrm{SiO}_{2}-\mathrm{PS}$ composite particles}

The starting point for the present study was to deform $\mathrm{SiO}_{2}-\mathrm{PS}$ composite particles, which is the most common combination of inorganic-organic colloids. The raspberry-like $\mathrm{SiO}_{2}-\mathrm{PS}$ composite particles were readily prepared by seeded emulsion 
polymerization of styrene with AIBN as an initiator and MMSmodified silica particles as seeds in pure aqueous medium according to a well-established protocol. ${ }^{24-26}$ The seeds are dispersed in water with PVP as a stabilizer, to which St monomer and AIBN initiator are added to initiate the polymerization. According to the literature, ${ }^{26}$ the nucleation process of PS in pure water medium occurs when the molecular weight was low due to its limited solubility. This leads to the formation of more nuclei and consequently smaller PS nodules, which resulted in raspberry-like particles. During the initial stage of the polymerization, the copolymerization of the styrene monomer and the methacrylate groups grafted onto the silica surface ensures that the copolymer component interacts strongly with the silica surface, and the formation of spherical PS nodules in the final stage is believed to be due to the minimization of the surface energy. ${ }^{46}$ The SEM and TEM images obtained for the composite particles are shown in Fig. 2. A well-defined, raspberry-like morphology is clearly visible, in which each silica sphere is closely surrounded by several PS nodules with a diameter of $\sim 165 \mathrm{~nm}$. The intensity-average diameter and the PDI of the composite particles were determined to be $474 \mathrm{~nm}$ and 0.02 (indicating good colloidal stability, see Fig. S1, ESI $\dagger$ ), respectively, and the silica content was around $40 \%$ by mass.

\subsection{Melting of raspberry-like $\mathrm{SiO}_{2}-\mathrm{PS}$ composite particles}

The raspberry-like $\mathrm{SiO}_{2}-\mathrm{PS}$ composite particles were subsequently subjected to melting in the presence of THF. In the previously reported protocols, ${ }^{41,42}$ the colloidal fusion was conducted in a THF/water medium. The deformation of the $\mathrm{SiO}_{2}-\mathrm{PS}$ clusters is based on the fact that the water soluble THF can act as a powerful plasticizer to make the PS shells soften and fuse very quickly. During this process, the shape of the PS
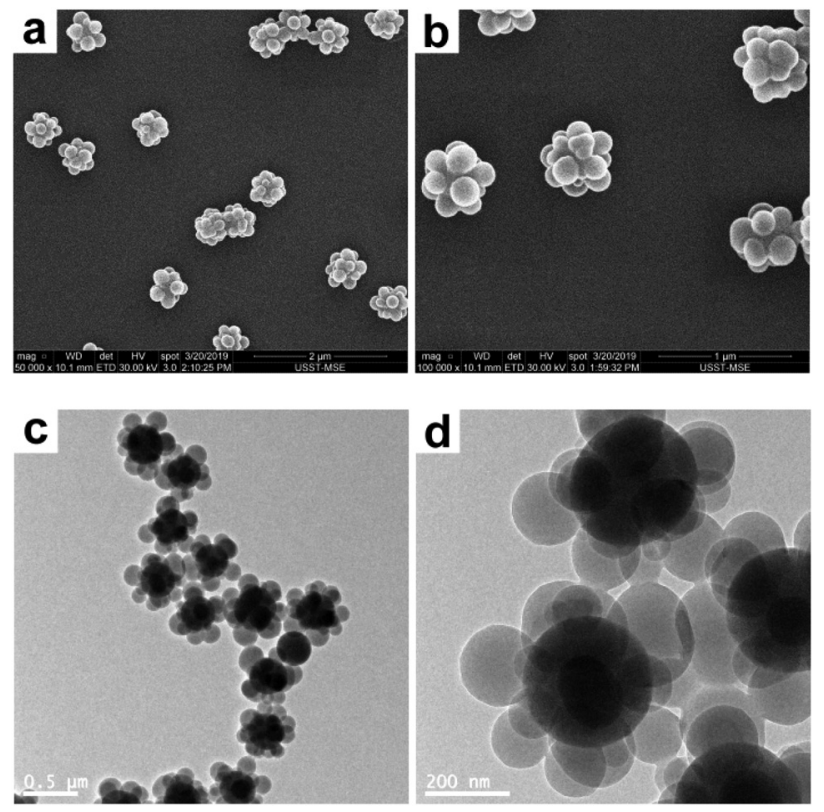

Fig. 2 SEM ( $a$ and $b$ ) and TEM ( $c$ and $d$ ) images at various magnifications of raspberry-like $\mathrm{SiO}_{2}-\mathrm{PS}$ composite particles. shell particles is heavily affected by the surface tension and they tend to adopt a variety of morphologies to minimize the surface energy. ${ }^{47}$ More specifically, the PS shell particles will simply minimize their own surface area by spreading over the surface of the $\mathrm{SiO}_{2}$ core particle to give energetically favorable spherical core-shell composite particles. ${ }^{48}$ It should be noted that there are two significant differences between the $\mathrm{SiO}_{2}-\mathrm{PS}$ composite particles in this work and those in Sacanna's work, which may influence the deformation of the composite particles. One is that a covalent bond is formed between the PS nodules and the $\mathrm{SiO}_{2}$ seed in this work, while the $\mathrm{SiO}_{2}$-PS particles are formed via electrostatic interactions in the previous work. Another one is that the size of the PS nodules in this work is only $\sim 165 \mathrm{~nm}$, much smaller than that in the previous work $(\sim 600 \mathrm{~nm})$. This is important, since polymer coronas below $400 \mathrm{~nm}$ were proved to be poor candidates for colloidal fusion as they readily coalesced and beaded up on the cores instead of wetting and compartmentalizing. ${ }^{42}$

Our preliminary control experiment confirmed that melting in a previously used THF/water medium (entry 1 in Table 1, see Fig. 3) could not produce the expected deformation of the composite particles. At first sight, the raspberry-like morphology was essentially unchanged. Close inspection of these SEM and TEM images indicated that deformation occurred to some extent: many PS corona particles were diminished and melted around the $\mathrm{SiO}_{2}$ core particles, leading to sparser coating, while several swollen PS corona particles were also observed. This is in contrast to that reported previously for the $\mathrm{SiO}_{2}-\mathrm{PS}$ composite particles prepared by the heteroaggregation process, where obvious deformation was observed. ${ }^{42}$

However, the melting of the composite particles in a THF/ ethanol medium under otherwise identical conditions (entry 4 in Table 1) invariably led to obvious deformation. Ethanol instead of water was chosen as the melting medium because it is assumed that PS is more easily swollen by ethanol, which has a closer solubility parameter value (12.7) to PS (8.7-9.1) than water (23.2). ${ }^{49}$ Fig. 4 shows the SEM and TEM images of the $\mathrm{SiO}_{2}$-PS composite particles obtained after being melted in a THF/ethanol medium with $30 \%$ THF. It is clear that almost all the composite particles were deformed from the raspberry-like morphology to a near-spherical morphology, since the PS nodules would simply minimize their surface area by taking a spherical shape. ${ }^{42}$ More specifically, most of the original individual PS nodules disappeared and fused together, or diminished (if any). However, the melting process was imperfect, leaving most of the silica cores with incomplete surface coverage. There are two possible reasons for the imperfect melting. First, the strong anchoring of the PS corona particles at the surface of the $\mathrm{SiO}_{2}$ core particle via covalent bonds might restrict the flow of the PS melts. Second, the relatively small PS nodule size makes the homogeneous deformation of the composite particles more difficult, as mentioned above. However, to the best of our knowledge, it is difficult to prepare raspberry-like $\mathrm{SiO}_{2}$-PS composite particles with larger polymer coronas $(>400 \mathrm{~nm})$ by seeded polymerization, even if larger $\mathrm{SiO}_{2}$ seeds are used. ${ }^{5}$ This is probably due, at least in part, to 
Table 1 Melting conditions of the submicrometer-sized raspberry-like $\mathrm{SiO}_{2}-\mathrm{PS}$ composite particles

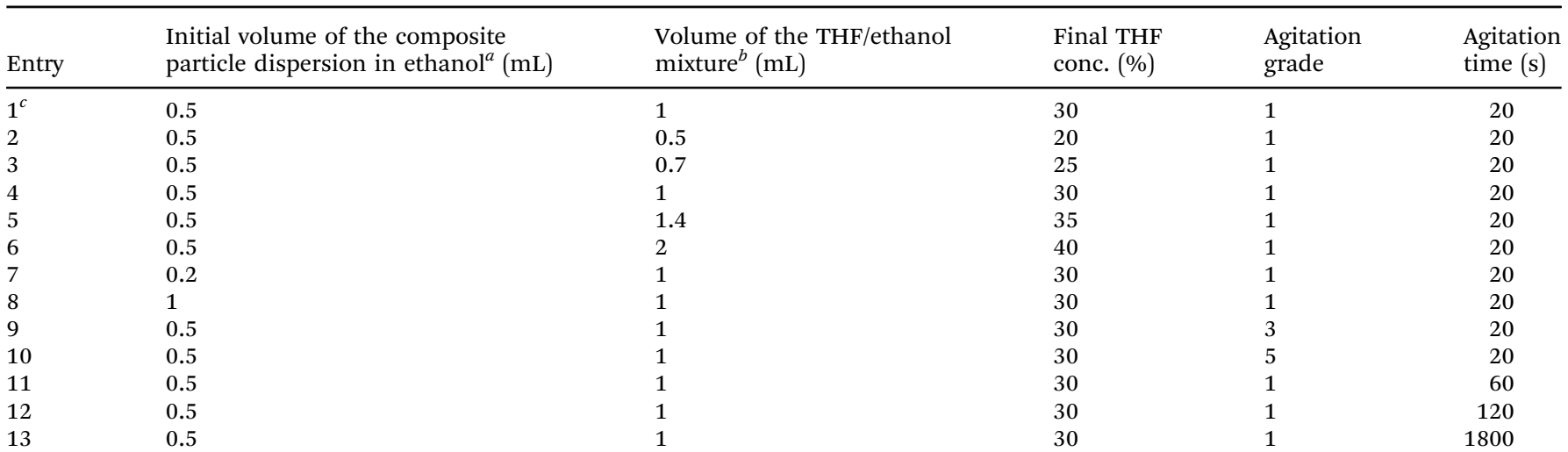

${ }^{a}$ The concentration (conc.) of the composite particle dispersion in ethanol was $8.0 \mathrm{~g} \mathrm{~L}^{-1}$, and the dispersion was diluted with ethanol to $1 \mathrm{~mL}$ if necessary prior to melting. ${ }^{b}$ The THF concentration in the THF/ethanol mixture was $60 \mathrm{vol} \%{ }^{c}{ }^{c}$ Using the THF/water medium instead of the THF/ethanol medium.
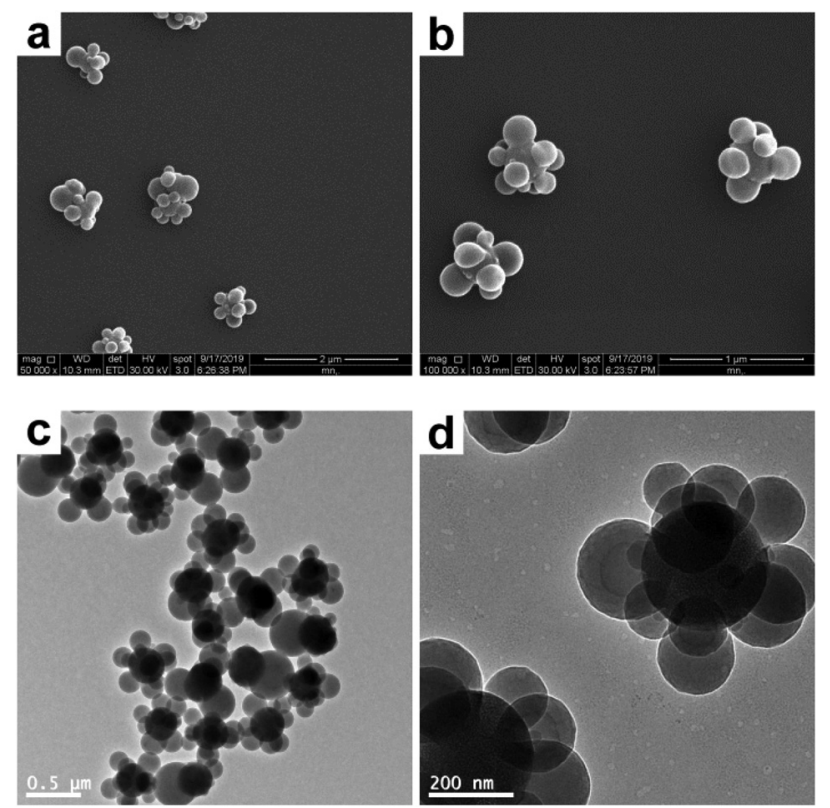

Fig. 3 SEM ( $a$ and $b$ ) and TEM (c and d) images at various magnifications of $\mathrm{SiO}_{2}-\mathrm{PS}$ composite particles after melting in a THF/water medium with $30 \%$ THF (entry 1 in Table 1).

the inorganic nature of $\mathrm{SiO}_{2}$ seeds, which can not be swollen by monomers.

\subsection{Variation of the deformation parameters for the melting of raspberry-like $\mathrm{SiO}_{2}-\mathrm{PS}$ composite particles}

To identify the conditions for the deformation of the raspberrylike $\mathrm{SiO}_{2}-\mathrm{PS}$ composite particles by colloidal fusion, a series of melting experiments were conducted by varying the following parameters: (i) the THF concentration, (ii) the composite particle concentration, (iii) the agitation time and (iv) the agitation rate, as summarized in Table 1.

First of all, the THF concentration in the THF/ethanol medium was systematically varied in order to tune the morphology of the composite particles. More specifically, the
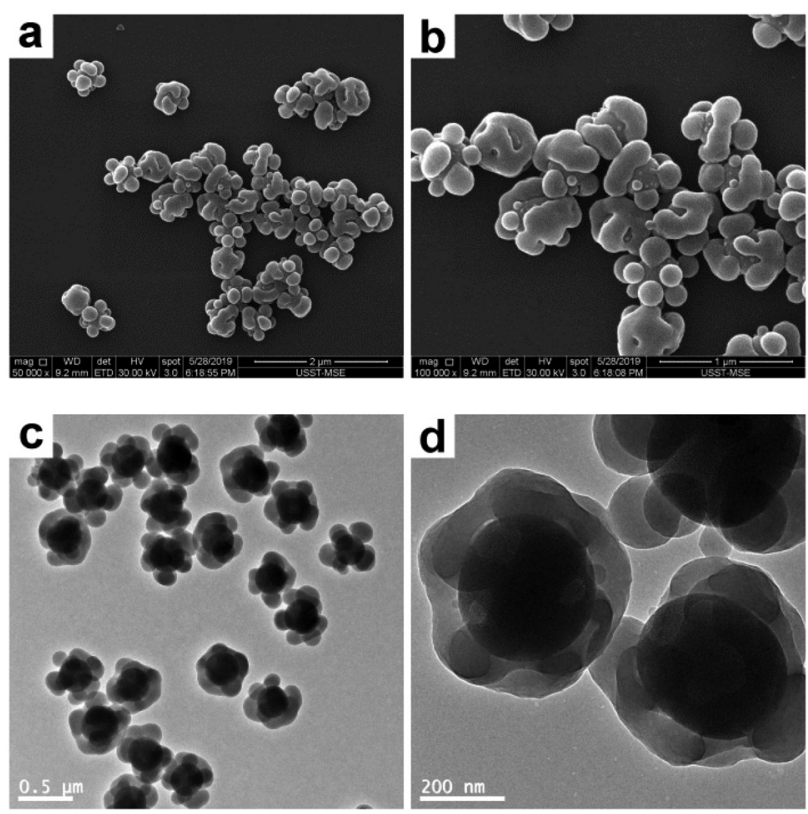

Fig. 4 SEM ( $a$ and $b$ ) and TEM ( $c$ and d) images at various magnifications of $\mathrm{SiO}_{2}-\mathrm{PS}$ composite particles after melting in a THF/ethanol medium with 30\% THF (entry 4 in Table 1).

raspberry-like $\mathrm{SiO}_{2}-\mathrm{PS}$ composite particles were melted in a THF/ethanol medium with $20-40 \%$ THF. Representative SEM and TEM images of the composite particles obtained are shown in Fig. 5 and 6, respectively. At the lowest THF concentration of $20 \%$, it seemed that the composite particles did not appear to show any significant morphological changes (Fig. 5a and 6a), suggesting that this THF concentration was not enough to make PS flow. A further increase of the THF concentration to $25 \%$ led to fusion of the PS nodules and wetting of the silica cores, although some individual nodules were still present (Fig. 5b and 6b). The optimum THF concentration appeared to be $30 \%$, as discussed above. A higher THF concentration led to more irregular composite particles. When the THF concentration was $35 \%$, most of the PS nodules were melted and 

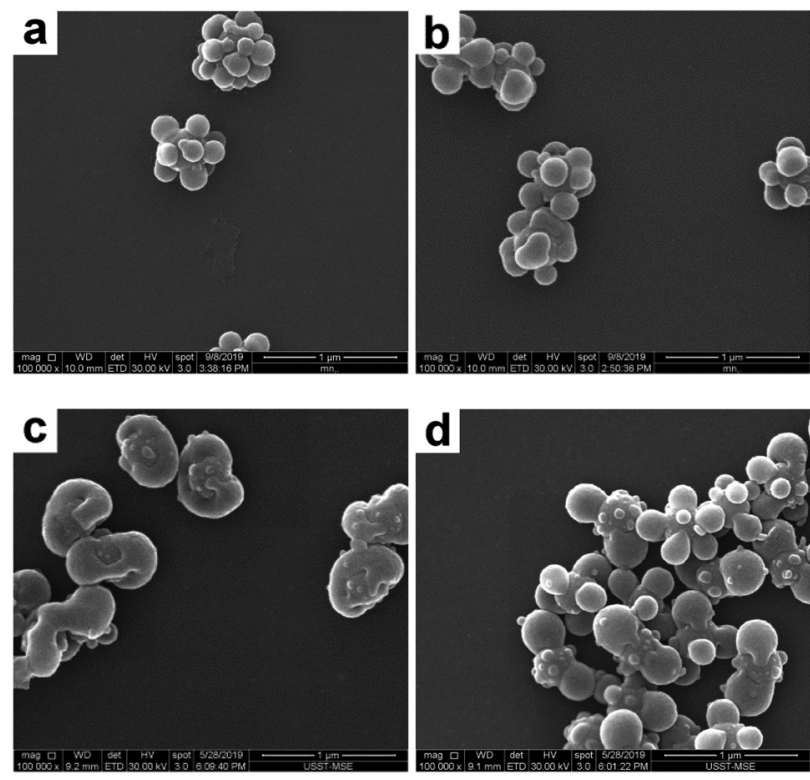

Fig. $5 \mathrm{SEM}$ images of $\mathrm{SiO}_{2}-\mathrm{PS}$ composite particles after melting in a THF/ethanol medium with various THF concentrations: (a) 20\% (entry 2 in Table 1); (b) 25\% (entry 3 in Table 1); (c) 35\% (entry 5 in Table 1); and (d) 40\% (entry 6 in Table 1).
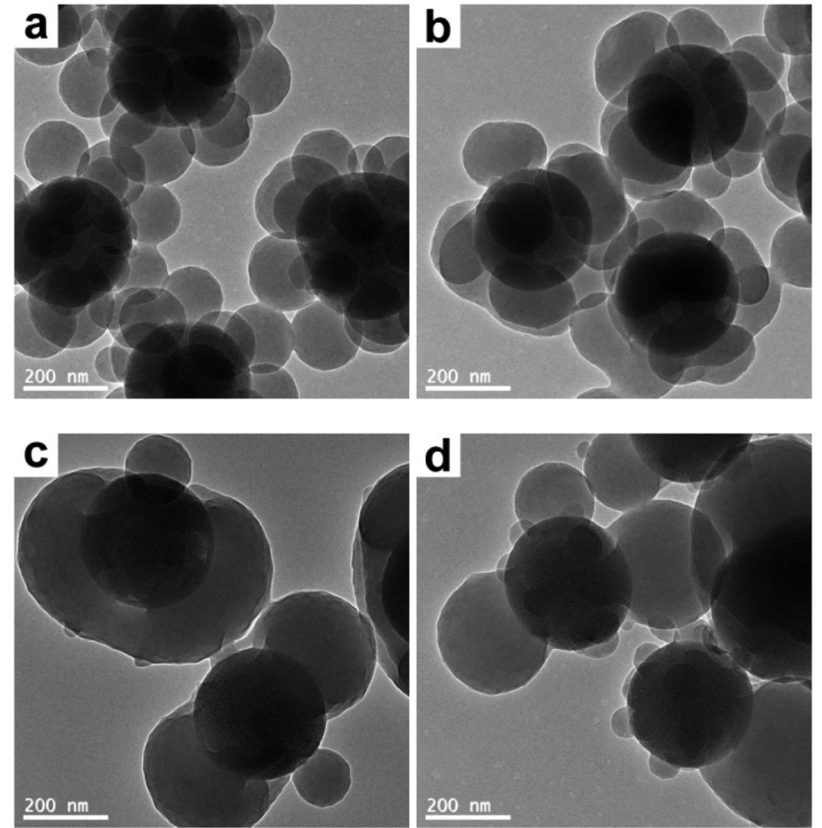

Fig. 6 TEM images of $\mathrm{SiO}_{2}-\mathrm{PS}$ composite particles after melting in a THF/ethanol medium with various THF concentrations: (a) 20\% (entry 2 in Table 1); (b) 25\% (entry 3 in Table 1); (c) 35\% (entry 5 in Table 1); and (d) 40\% (entry 6 in Table 1).

tended to move towards both ends (Fig. $5 \mathrm{c}$ and $6 \mathrm{c}$ ). At a THF concentration of $40 \%$, some dumbbell-like (Fig. 5d and 6d) composite particles were observed. Furthermore, the silica seeds were poorly coated, and some PS nodules were highly swollen while individual nodules also coexisted. This further confirmed that although a higher THF concentration might allow the PS nodules to behave as a liquid, homogenous coating around the core was restricted by the small size of the PS nodules. On the other hand, obvious coalescence was not observed between the composite particles when the THF concentration was in the range of $20-35 \%$. This should be attributed to the use of PVP as the stabilizer in the seeded emulsion polymerization process, which adsorbs onto the particle surface and prevents aggregation by steric stabilization. ${ }^{50}$ However, since THF is a good solvent for the PS coronas, a further increase of THF to $40 \%$ led to slight coalescence between adjacent particles (see Fig. 5d), and substantial coagulation occurred at 50\% THF. In summary, a moderate THF concentration is a prerequisite for a relatively regular deformation.

The effect of varying the composite particle concentration was investigated in a THF/ethanol medium with $30 \%$ THF. As shown in Fig. S2 (ESI $\dagger$ ), the composite particles did not appear to show significant morphological changes when the composite particle concentration ranged from 0.8 to $4.0 \mathrm{~g} \mathrm{~L}^{-1}$ (entries 7 and 8 in Table 1, respectively). Thus, it can be concluded that the fusion process was independent of the composite particle concentration. The effect of varying the agitation rate was investigated in a THF/ethanol medium with $30 \%$ THF with higher agitation rates. The agitation rate was varied to grade 3 and grade 5 (entries 9 and 10 in Table 1, respectively). Note that the mixer is infinitely adjustable, and a higher grade just means a higher agitation rate. Representative SEM and TEM images of the resulting particles are shown in Fig. S3 (ESI $\dagger$ ). It seems that higher agitation rates had little effect on the morphology of the final composite particles, which suggested that the composite particle morphology was essentially independent of the agitation rate. This is due to the fact that the deformation is a thermodynamic process, which is hardly affected by the kinetic mixing conditions. Fig. S4 (ESI $\dagger$ ) shows SEM and TEM images of the $\mathrm{SiO}_{2}-\mathrm{PS}$ composite particles after melting in a THF/ethanol medium with $30 \%$ THF at longer agitation times. Compared to the deformed particles obtained under the standard conditions, although the melting time was increased from $20 \mathrm{~s}$ to $60 \mathrm{~s}$ and $120 \mathrm{~s}$ (entries 11 and 12 in Table 1, respectively), no apparent change in the morphology of the composites was observed. A further increase of the agitation time to $30 \mathrm{~min}$ (entry 13 in Table 1) also led to similar morphologies, indicating that $20 \mathrm{~s}$ was enough for the deformation process if the THF concentration was high enough. ${ }^{51}$

\subsection{Synthesis of PGMA-PS composite particles}

In order to synthesize raspberry-like polymer composite particles with larger polymer coronas, micrometer-sized, near-monodisperse PGMA-PS composite particles were prepared by seeded emulsion polymerization of styrene using the AIBN initiator and PGMA seeds according to a protocol previously reported by Zhang et $a .^{18}$ PGMA was selected as the seed in the original work since it has abundant epoxy groups on its surface, which can offer some interesting properties for biological applications. These composite particles exhibit a well-defined, raspberry-like morphology, as judged by the SEM and TEM images shown in Fig. 7. The average diameter of the composite particles was determined to be $4.33 \mu \mathrm{m}$, and the average 

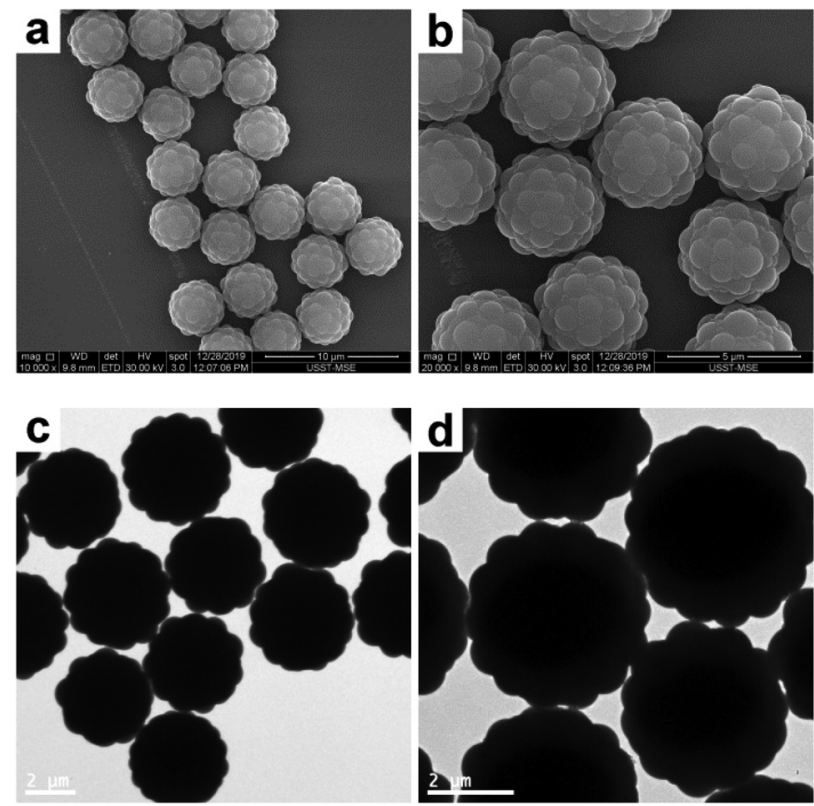

Fig. 7 SEM ( $a$ and $b$ ) and TEM (c and d) images at various magnifications of raspberry-like PGMA-PS composite particles.

size of the PS protrusions on the surface of the PGMA-PS microparticles was determined to be $0.92 \mu \mathrm{m}$ by subtracting the average diameter of PGMA. This large size of the PS coronas should favor the subsequent deformation. Furthermore, in comparison to those in the raspberry-like $\mathrm{SiO}_{2}-\mathrm{PS}$ composite particles, it seemed that the PGMA cores in the raspberry-like PGMA-PS composite particles were completely covered by the PS coronas since the PS coronas were grown from the styreneswollen PGMA seed particles. This would also be beneficial for the subsequent deformation.

\subsection{Melting of raspberry-like PGMA-PS composite particles}

Following a similar procedure to that for $\mathrm{SiO}_{2}-\mathrm{PS}$ composite particles, the raspberry-like PGMA-PS composite particles were subjected to melting in the presence of THF. In contrast to the $\mathrm{SiO}_{2}-\mathrm{PS}$ composite particles, the preliminary control experiment for the PGMA-PS composite particles confirmed that the melting conducted in a THF/ethanol medium with $30 \%$ THF led to complete coagulation. Presumably this is because the PGMA-PS composite particles were synthesized using SDS as the surfactant, which has poor solubility in ethanol (but good solubility in water). Accordingly, the dispersibility of the PGMA-PS composite particles in ethanol is poor. Instead, SEM and TEM studies suggested that the original raspberrylike surfaces were replaced with much smoother particle surfaces after being melted in a THF/water medium with $30 \%$ THF (see Fig. 8). These micrographs also revealed that approximately spherical particles of $\sim 4.12 \mu \mathrm{m}$ diameter were obtained. Although poor contrast images were achieved by TEM, the smoother surface and significantly increased size of the composite particles compared to the original PGMA particles (see Fig. S5, ESI $\dagger$ ) suggested that a well-defined core-shell morphology was obtained.
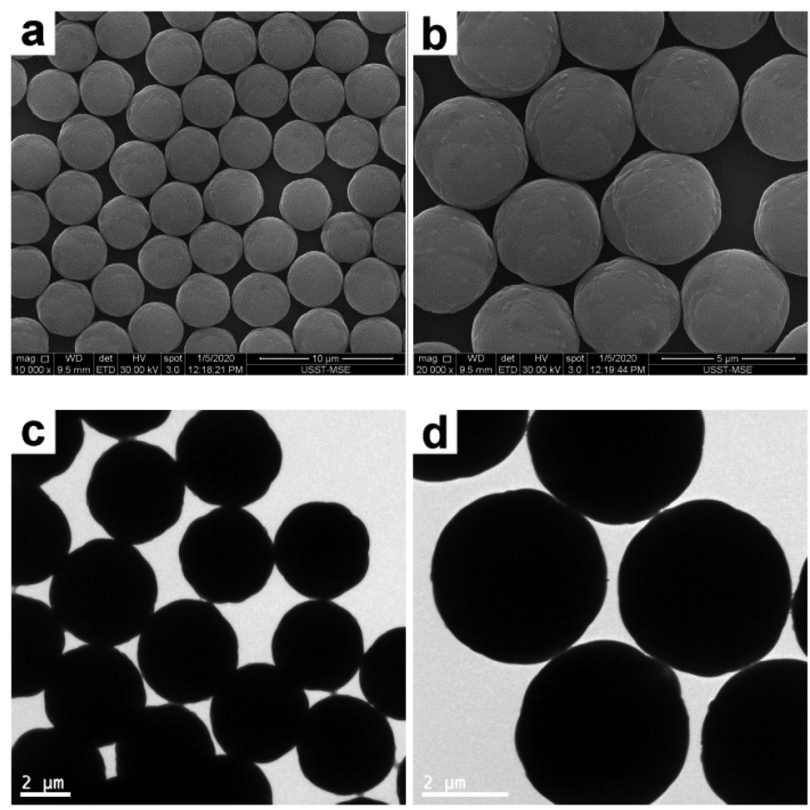

Fig. 8 SEM ( $a$ and $b$ ) and TEM (c and $d$ ) images at various magnifications of PGMA-PS composite particles after melting in a THF/water medium with 30\% THF (entry 5 in Table 2).

According to the above observations on the $\mathrm{SiO}_{2}$-PS system, the morphology of the composite particles was significantly affected by the THF concentration in the melting medium. Therefore, for the melting experiments of the PGMA-PS composite particles, the THF concentration in the THF/water medium was systematically varied (from $15 \%$ to $35 \%$ by volume), as summarized in Table 2. Representative SEM images of the composite particles obtained are shown in Fig. 9. At a low THF concentration of $15 \%$, no significant morphological change was observed (Fig. 9a), suggesting that this THF concentration was too low to make PS flow; at $20 \%$ THF, it seemed that the coronas began to deform and wet their cores (Fig. 9b); a further increase of the THF concentration to $25 \%$ resulted in an appreciable reduction in surface roughness (Fig. 9c); and at higher THF concentrations of $30 \%$ and $35 \%$, composite particles with much smoother surfaces were observed (Fig. 8b and 9d). However, significant coagulum was observed at $35 \% \mathrm{THF}$, which suggested that this was close to the maximum THF concentration for successful deformation. Although it is difficult to quantify the level of deformation with accuracy, the reduction of the size of the resulting composite particles may reflect the contraction of the PS coronas. The average diameter of the PGMA-PS particles decreased to $4.30 \mu \mathrm{m}$ at $15 \% \mathrm{THF}, 4.27 \mu \mathrm{m}$ at $20 \%$ THF, $4.19 \mu \mathrm{m}$ at $25 \% \mathrm{THF}, 4.12 \mu \mathrm{m}$ at $30 \% \mathrm{THF}$ and $4.11 \mu \mathrm{m}$ at $35 \%$ THF, which corresponded to a PS diameter of $0.91 \mu \mathrm{m}$, $0.89 \mu \mathrm{m}, 0.85 \mu \mathrm{m}, 0.82 \mu \mathrm{m}$ and $0.81 \mu \mathrm{m}$, respectively. This indicated that the surface roughness of the composite particles could be easily controlled by varying the THF concentration. Overall, a larger PS corona is considered to be essential for successful deformation by colloidal fusion. In addition, a suitable melting medium and a moderate THF concentration 
Table 2 Melting conditions of the micrometer-sized raspberry-like PGMA-PS composite particles

\begin{tabular}{|c|c|c|c|c|c|}
\hline Entry & $\begin{array}{l}\text { Initial volume of the composite particle } \\
\text { dispersion in water }{ }^{a}(\mathrm{~mL})\end{array}$ & $\begin{array}{l}\text { Volume of the THF/water } \\
\text { mixture }^{b}(\mathrm{~mL})\end{array}$ & $\begin{array}{l}\text { Final THF } \\
\text { conc. }(\%)\end{array}$ & $\begin{array}{l}\text { Agitation } \\
\text { grade }\end{array}$ & $\begin{array}{l}\text { Agitation } \\
\text { time (s) }\end{array}$ \\
\hline $1^{c}$ & 0.5 & 3 & 30 & 1 & 20 \\
\hline 2 & 0.5 & 0.6 & 15 & 1 & 20 \\
\hline 3 & 0.5 & 1 & 20 & 1 & 20 \\
\hline 4 & 0.5 & 1.67 & 25 & 1 & 20 \\
\hline 5 & 0.5 & 3 & 30 & 1 & 20 \\
\hline 6 & 0.5 & 7 & 35 & 1 & 20 \\
\hline
\end{tabular}

${ }^{a}$ The concentration of the composite particle dispersion in water was $44.4 \mathrm{~g} \mathrm{~L}^{-1}$, and the dispersion was diluted with water to $1 \mathrm{~mL}$ prior to melting. ${ }^{b}$ The THF concentration in the THF/water mixture was $40 \mathrm{vol} \%{ }^{c}{ }^{c}$ Using the THF/ethanol medium instead of the THF/water medium.
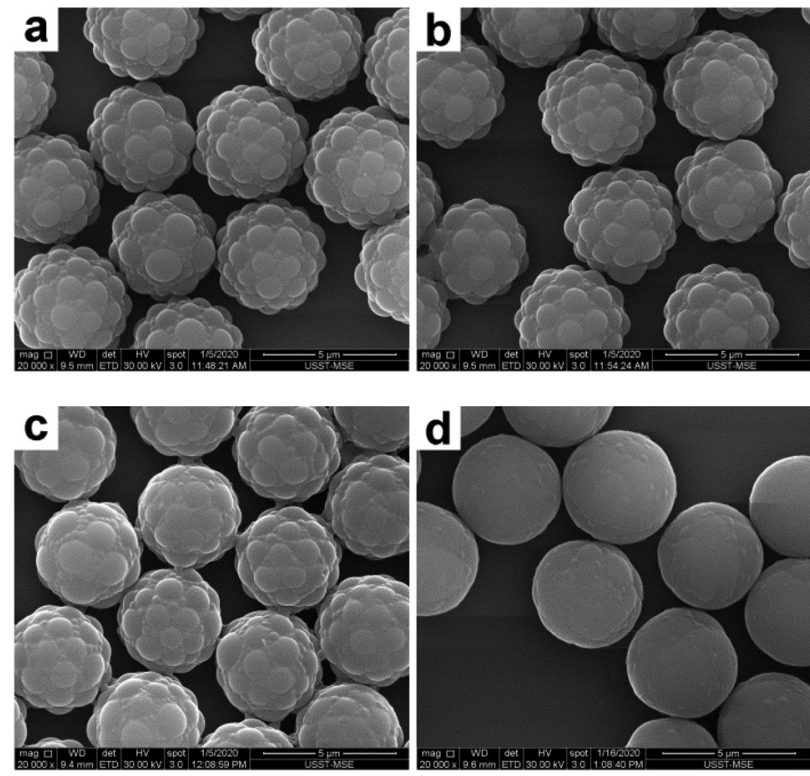

Fig. 9 SEM images of PGMA-PS composite particles after melting in a THF/water medium with various THF concentrations: (a) $15 \%$ (entry 2 in Table 2); (b) 20\% (entry 3 in Table 2); (c) 25\% (entry 4 in Table 2); and (d) $35 \%$ (entry 6 in Table 2).

in the melting medium are also prerequisites for successful deformation.

\section{Conclusions}

In summary, we have demonstrated the deformation of raspberrylike polymer composite particles with polymer coronas through the colloidal fusion method. Submicrometer-sized $\mathrm{SiO}_{2}-\mathrm{PS}$ or micrometer-sized PGMA-PS composite particles with a welldefined raspberry-like morphology were first prepared via seeded emulsion polymerization of styrene, and then the two types of particles were melted in different media in the presence of THF, respectively. The melting experiments based on $\mathrm{SiO}_{2}-\mathrm{PS}$ composite particles were less successful but provided some interesting results. The raspberry-like $\mathrm{SiO}_{2}$-PS particles were slightly deformed in a THF/water medium but markedly deformed in a THF/ethanol medium. Furthermore, the morphology of the composite particles was significantly affected by the THF concentration in the medium but essentially insensitive to the particle concentration, agitation time and agitation rate. Finally, well-defined core-shell composite particles were formed based on raspberry-like PGMA-PS composite particles. However, unlike the $\mathrm{SiO}_{2}$-PS composite particles, the PGMA-PS composite particles could deform in a THF/water medium but not in a THF/ ethanol medium. The THF concentration in the medium also had an obvious effect on the morphology of the composite particles, indicating that the surface roughness of the composite particles could be easily tuned by varying the THF concentration. Thus, it can be concluded that the key to successful deformation by colloidal fusion is the use of raspberry-like particles having larger polymer coronas in combination with a suitable melting medium and a moderate THF concentration in the melting medium. This work is expected to provide some insights regarding controlling the surface roughness of raspberry-like preformed polymer composite particles with polymer coronas.

\section{Conflicts of interest}

There are no conflicts to declare.

\section{Acknowledgements}

This work is supported by the National Natural Science Foundation of China (51973117, 51503123), Program of Young Eastern Scholar from Shanghai Institutions of Higher Learning (QD2015014) and University of Shanghai for Science and Technology.

\section{Notes and references}

1 S. P. Armes, S. Gottesfeld, J. G. Beery, F. Garzon and S. F. Agnew, Polymer, 1991, 32, 2325-2330.

2 M. Gill, J. Mykytiuk, S. P. Armes, J. L. Edwards, T. Yeates, P. J. Moreland and C. Mollett, J. Chem. Soc., Chem. Commun., 1992, 108-109.

3 S. Maeda and S. P. Armes, J. Colloid Interface Sci., 1993, 159, 257-259.

4 J. A. Balmer, A. Schmid and S. P. Armes, J. Mater. Chem., 2008, 18, 5722-5730.

5 H. Zou, S. Wu and J. Shen, Chem. Rev., 2008, 108, 3893-3957.

6 H. Zou and S. P. Armes, Polym. Chem., 2012, 3, 172-181. 
7 H. Zou and H. Schlaad, Colloid Polym. Sci., 2014, 292, 1693-1700.

8 H. Zou, D. Miao, H. Sun and X. Wang, Langmuir, 2018, 34, 14302-14308.

9 Y. Zhao, Z. Chen, X. Zhu and M. Möller, Macromolecules, 2016, 49, 1552-1562.

10 C. Graf, D. L. J. Vossen, A. Imhof and A. van Blaaderen, Langmuir, 2003, 19, 6693-6700.

11 K. Zhang, H. Chen, X. Chen, Z. Chen, Z. Cui and B. Yang, Macromol. Mater. Eng., 2003, 288, 380-385.

12 H. Zou and H. Schlaad, J. Polym. Sci., Part A: Polym. Chem., 2015, 53, 1260-1267.

13 S. Reculusa, C. Poncet-Legrand, S. Ravaine, C. Mingotaud, E. Duguet and E. Bourgeat-Lami, Chem. Mater., 2002, 14, 2354-2359.

14 A. Perro, S. Reculusa, E. Bourgeat-Lami, E. Duguet and S. Ravaine, Colloids Surf., A, 2006, 284-285, 78-83.

15 J. L. Luna-Xavier, A. Guyot and E. Bourgeat-Lami, J. Colloid Interface Sci., 2002, 250, 82-92.

16 J. L. Luna-Xavier, A. Guyot and E. Bourgeat-Lami, Polym. Int., 2004, 53, 609-617.

17 X. J. Cheng, M. Chen, S. X. Zhou and L. M. Wu, J. Polym. Sci., Part A: Polym. Chem., 2006, 44, 3807-3816.

18 L. Tian, X. J. Li, P. P. Zhao, X. Chen, Z. Ali, N. Ali, B. L. Zhang, H. P. Zhang and Q. Y. Zhang, Macromolecules, 2015, 48, 7592-7603.

19 Y. H. Zhang, Q. C. Zou, X. W. Shu, Q. Q. Tang, M. Chen and L. M. Wu, J. Colloid Interface Sci., 2009, 336, 544-550.

20 S. W. Zhang, S. X. Zhou, Y. M. Weng and L. M. Wu, Langmuir, 2005, 21, 2124-2128.

21 J. Zhou, S. W. Zhang, X. G. Qiao, X. Q. Li and L. M. Wu, J. Polym. Sci., Part A: Polym. Chem., 2006, 44, 3202-3209.

22 X. G. Qiao, M. Chen, J. Zhou and L. M. Wu, J. Polym. Sci., Part A: Polym. Chem., 2007, 45, 1028-1037.

23 D. Xu, M. Wang, X. Ge, M. H.-W. Lam and X. Ge, J. Mater. Chem., 2012, 22, 5784-5791.

24 D. Nguyen, E. Duguet, E. Bourgeat-Lami and S. Ravaine, Langmuir, 2010, 26, 6086-6090.

25 D. Nguyen, S. Ravaine, E. Bourgeat-Lami and E. Duguet, J. Mater. Chem., 2010, 20, 9392-9400.

26 Z. Zhang, H. Shao, X. Zhou, L. Zhao, H. Liu, X. Ji and H. Liu, Mater. Chem. Phys., 2017, 195, 105-113.

27 M. Chen, L. M. Wu, S. X. Zhou and B. You, Macromolecules, 2004, 37, 9613-9619.

28 M. Chen, S. X. Zhou, B. You and L. M. Wu, Macromolecules, 2005, 38, 6411-6417.
29 X. Du, X. M. Liu, H. M. Chen and J. H. He, J. Phys. Chem. C, 2009, 113, 9063-9070.

30 Z. Qian, Z. Zhang, L. Song and H. Liu, J. Mater. Chem., 2009, 19, 1297-1304.

31 J.-F. Dechézelles, V. Malik, J. J. Crassousbc and P. Schurtenberger, Soft Matter, 2013, 9, 2798-2802.

32 M. Yu, Q. Wang, Z. Min, Q. Deng and D. Chen, RSC Adv., 2017, 7, 39471-39479.

33 Y. C. Liu, M. L. Li and G. F. Chen, J. Mater. Chem. A, 2013, 1, 930-937.

34 Y. Lan, Y. C. Wu, A. Karas and O. A. Scherman, Angew. Chem., Int. Ed., 2014, 53, 2166-2169.

35 R. Guo, X. Chen, X. Zhu, A. Dong and J. Zhang, RSC Adv., 2016, 6, 40991-41001.

36 T. J. Yao, C. X. Wang, J. Wu, Q. Lin, H. Lv, K. Zhang, K. Yu and B. Yang, J. Colloid Interface Sci., 2009, 338, 573-577.

37 N. Ali, B. L. Zhang, H. P. Zhang, W. Zaman, X. J. Li, W. Li and Q. Y. Zhang, Colloids Surf., A, 2015, 472, 38-49.

38 H. Zou, D. Wu, H. Sun, S. W. Chen and X. Wang, Appl. Surf. Sci., 2018, 436, 1083-1092.

39 J. W. Li, S. Sihler and U. Ziener, Langmuir, 2019, 35, 6161-6168.

40 S. C. Thickett and G. H. Teo, Polym. Chem., 2019, 10, 2906-2924.

41 Z. Gong, T. Hueckel, G. R. Yi and S. Sacanna, Nature, 2017, 550, 234-238.

42 T. Hueckel and S. Sacanna, ACS Nano, 2018, 12, 3533-3540.

43 M. Okubo, N. Miyachi and Y. Lu, Colloid Polym. Sci., 1994, 272, 270-275.

44 R. H. Ottewill, A. B. Schofield, J. A. Waters and N. St. J. Williams, Colloid Polym. Sci., 1997, 275, 274-283.

45 W. Stöber, A. Fink and E. Bohn, J. Colloid Interface Sci., 1968, 26, 62-69.

46 S. Reculusa, C. Mingotaud, E. Bourgeat-Lami, E. Duguet and S. Ravaine, Nano Lett., 2004, 4, 1677-1682.

47 S. Sacanna, M. Korpics, K. Rodriguez, L. Colón-Meléndez, S.-H. Kim, D. J. Pine and G. R. Yi, Nat. Commun., 2013, 4, 1688.

48 H. G. Wang, B. H. Li, A. G. Yodh and Z. X. Zhang, Angew. Chem., Int. Ed., 2016, 55, 9952-9955.

49 M. J. He, H. D. Zhang, W. X. Chen and X. X. Dong, Polymer Physics, Fudan University Press, 2014.

$50 \mathrm{H}$. Zou and X. Wang, Langmuir, 2017, 33, 1471-1477.

51 M. Z. Liu, X. L. Zheng, F. Y. Dong, M. D. Ward and M. Weck, Chem. Mater., 2018, 30, 6903-6907. 